Prepared as part of the

USGS Greater Everglades Priority Ecosystem Sciences and National Research Programs

in cooperation with the

South Florida Water Management District and Everglades National Park

\title{
Surface-Water Exchange through Culverts beneath State Road 9336 within Everglades National Park, 2004-05
}

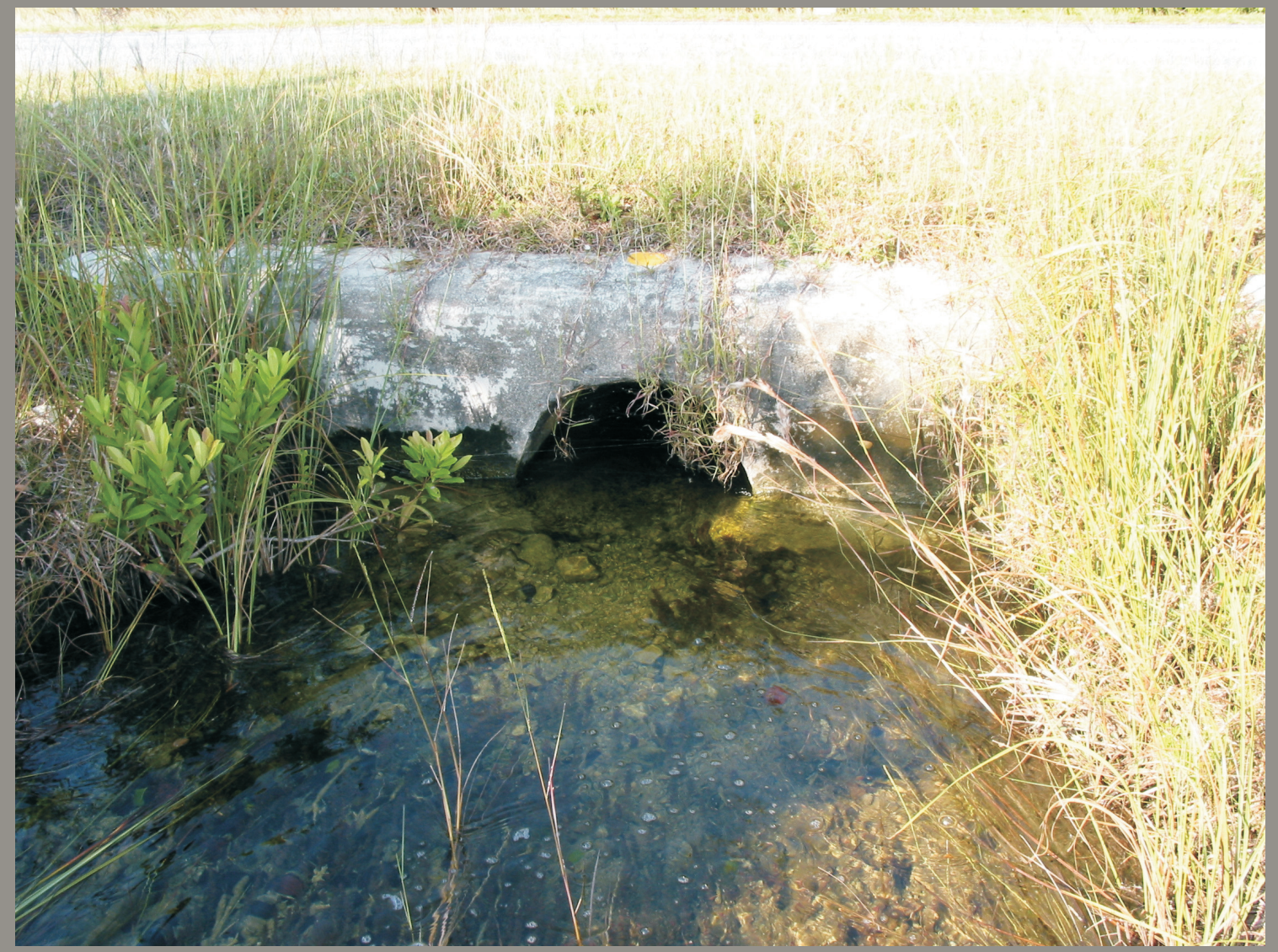

Data Series 358

U.S. Department of the Interior

U.S. Geological Survey 
